\title{
POTENSI DAN PRIORITAS INDUSTRI KREATIF SKALA MIKRO, KECIL DAN MENENGAH DI PROVINSI BANTEN
}

\section{POTENTIAL AND PRIORITY MICRO, SMALL AND MEDIUM SCALE CREATIVE INDUSTRIES IN BANTEN PROVINCE}

(disubmit 18 November 2020, direvisi 03 Desember 2020, diterima 05 Desember 2020)

\author{
Sugeng Setyadi ${ }^{1}$ dan Moh Sofyan Budiarto ${ }^{2}$ \\ ${ }^{1}$ Fakultas Ekonomi Bisnis, Universitas Sultan Ageng Tirtayasa, Jl. Raya Jakarta Km.4, \\ Pakupatan Serang Banten \\ ${ }^{2}$ Badan Perencanaan Pembangunan Daerah Provinsi Banten, Jl. Syeh Nawawi Al Bantani, \\ KP3B Palima Serang Banten \\ Corresponding Author: sugeng.setyadi@untirta.ac.id, budiarto.sofyan@gmail.com
}

\begin{abstract}
ABSTRAK
Ekonomi kreatif merupakan salah satu sektor yang diharapkan mampu menjadi kekuatan nasional dan provinsi Banten dengan kontribusi terhadap PDB meningkat dari tahun ke tahun. Diperlukan pemetaan terhadap potensi dan prioritas sektor industri kreatif di provinsi Banten untuk menentukan rencana aksi dan strategi pengembangan. Penelitian ini bertujuan untuk menganalisis potensi dan prioritas industri kreatif skala kecil dan menengah di Provinsi Banten melalui indikator indikator yang bersifat kualitatif. Penelitian menggunakan metode diskriptif kualitatif dengan melakukan survei terhadap pelaku industri kreatif di provinsi Banten. Data primer diperoleh dengan metode wawancara, dan kuisioner sedangkan data sekunder diperoleh dari data yang relevan dari sumber lain seperti BPS, Disperindag dan studi literature. Analisa data menggunakan Analytical Hyrachy Process (AHP) merupakan pendekatan pengambilan keputusan yang dirancang untuk memberikan solusi dari permasalahan yang menyangkut kriteria yang bersifat komplek, menentukan prioritas pilihan-pilihan dengan banyak kriteria, dan menentukan model alternatif untuk menyelesaikan bermacam-macam masalah. Hasil perhitungan AHP dengan penyilangan Kriteria Prioroitas dengan Prioritas Subsektor Ekraf, didapatkan angka 0,496243386 pada posisi pertama untuk Kriya, 0,404603175 untuk subsektor Fesyen pada posisi kedua dan 0,099153439 untuk Subsektor Kuliner pada posisi ketiga. Ketiga Subsektor Ekoomi kreatif ini menjadi Sub sektor yang paling dominan dipilih oleh responden dan posisi peringkat diatas menjadi gambaran bagi pemerintah untuk memberikan stimulus lebih pada subsektor yang ada dan menjadi kekuatan utama sektor industri kreatif skala kecil dan menengah di Banten.

Kata Kunci: Pemetaan, Potensi, Industri Kreatif Menengah, Provinsi Banten
\end{abstract}

\begin{abstract}
The creative economy is one of the sectors that is expected to become a national strength and the province of Banten with the contribution to GDP increasing from year to year. Mapping of the potentials and priorities of the creative industry sector in Banten province is required to determine action plans and development strategies. The research objective is to mapping the potential and priority of small and medium the creative industri in Banten Province through indicators with qualitative approach. Research used qualitative descriptive methods by
\end{abstract}


conducting a survey of creative industri actors in Banten province. Primary data was obtained by interview method, and questionnaire while secondary data was obtained from relevant data from other sources such as BPS, Disperindag and literature study. Data analysis using the Analytical Hyrachy Process (AHP) is a decision-making approach designed to provide solutions to problems involving complex criteria, determine priorities with multiple criteria, and determine alternative models to solve various problems. AHP calculation results by crossing the Priority Criteria with the Subsector's Priority Ekraf, obtained the number 0, 496243386 in the first position for Kriya, 0.404603175 for the Fashion sub-sector in the second position and 0.099153439 for the Culinary Subsector in the third position. The three subsectors of this creative economy become the most dominant subsector chosen by the respondents and the ranking position above becomes a picture for the government to provide more stimulus to the existing sub-sector micro, small and medium creative Industri sector in Banten Province. Keywords: Mapping, Potential, Small and Medium Entreprise, Banten Province

\section{PENDAHULUAN}

Indonesia memiliki potensi kekayaan sumberdaya alam seperti bahan tambang, minyak bumi, gas alam yang semakin terbatas jumlahnya. Dengan keterbatasan tersebut, sumber ekonomi lain seperti keragaman budaya, maupun sumberdaya manusia seperti kreativitas dan inovasi menjadi solusi dalam pembangunan nasional untuk mengoptimalkan berbagai potensi kekayaan yang dimilikinya. Ekonomi kreatif yang berbasis kepada modal kreativitas sumberdaya manusia, berpeluang mendorong dan meningkatkan daya saing bangsa Indonesia di masa depan.

Sumberdaya manusia berupa kemampuan untuk berkreasi, menciptakan inovasi dan nilai tambah, akan menjadi sumberdaya terbarukan yang tidak akan ada habisnya. Konsep 'ekonomi kreatif' merupakan hasil dari tranformasi struktur perekonomian dunia dimana terjadi perubahan pertumbuhan ekonomi berbasis sumber daya alam menjadi berbasis sumber daya manusia, dari era pertanian menjadi era industri serta informasi, (Bank Indonesia, 2015). Menurut Hawkins (2005) Ekonomi kreatif adalah ekonomi yang input dan outputnya berupa gagasan. Ekonomi Kreatif digerakkan oleh Industri kreatif, yaitu industri yang berasal dari pemanfaatan kreativitas, keterampilan serta bakat individu untuk menciptakan kesejahteraan serta lapangan pekerjaan melalui penciptaan dan pemanfaatan daya kreasi dan daya cipta individu. Industri kratif lahir sebagai akibat globalisasi yang berakibat tekanan persaingan antar Negara pada industri konvensionalyang bersifat skala besar, (Antariksa, ----- ). 
Kotribusi industri kreatif terhadap PDRB, penyediaan lapangan kerja, peningkatan ekspor terus meningkat seiring dengan berjalannya waktu. Masalah yang dihadapi oleh para pelaku industri kreatif skala mikro kecil dan menengah adalah dinamika dan karakteristik industri kreatif di Indonesia (Bank Indonesia, 2015), keterbatasan SDM, mutu dan standarisasi produk, manajemen proses rendah, (Sumartik dan Larassaty, 2016).

Menurut Himam (2016), Kontribusi Industri Kreatif Indonesia pada tahun 2014 sebesar $7.1 \%$ PDRB dengan proyeksi tahun 2019 sebesar $12 \%$. Dari sisi penyerapan tenaga kerja industri kreatif tahun 2014 sebesar 12 juta orang dan proyeksi serapan tahun 2019 sebesar 13 Juta orang. Kontribusi ekspor industri kreatif sebesar 5,8 \% dari PDRB tahun 2014 dan proyeksi tahun 2019 sebesar 10 \%, dari PDRB, (Himam, 2016). Dalam rangka memenuhi tercapainya target 2019, Pemerintah meluncurkan beberapa strategi pengembangan industri kreatif diantarana perluasan pasar ekspor produk kreatif, fasilitasi proses berupa ruang kreasi dan jaringan orang kreatif, fasilitasi rantai nilai ekonomi kreatif dan fasilitasi startup, (Hamdan 2016).

Kreativitas akan mendorong dihasilkannya produk dan jasa yang inovatif dan bernilai tambah tinggi sehingga kelak Indonesia tidak akan lagi bergantung pada ekspor bahan mentah, tetapi juga akan mampu mengekspor produk yang bernilai tambah tinggi. Kreativitas dan inovasi juga akan menjadikan warisan budaya dan kearifan lokal berkontribusi besar tidak hanya bagi perekonomian nasional namun juga bagi peningkatan citra bangsa Indonesia di mata dunia internasional.

Kemenparekraf telah mengidentifikasi sedikitnya terdapat tujuh isu strategis yang menjadi potensi sekaligus tantangan yang perlu mendapatkan perhatian para pemangku kepentingan industri kreatif mendatang, yaitu : Ketersediaan sumber daya kreaitf yang professional dan kompetitif; Ketersediaan sumber daya alam yang berkualitas beragam dan kompetitif dan sumber daya budaya yang dapat diakses secara mudah; Indusri Kreatif yang berdaya saing; Ketersediaan pembiayaanyand sesuai mudah diakses; Perluasan pasar bagi karya kreatif; Ketersediaan infrastruktur dan teknologi yang sesuai; dan Kelembagaan yang mendukung pengembangan ekonomi kreatif.

Menurut Hamdam (2016) Kontribusi industri kreatif kedepan akan semakin signifikan, melihat berbagai 
faktor pendukung seperti bonus demografi Indonesia, perkembangan gaya hidup digital, peningkatan jumlah kelas menengah, meningkatnya permintaan produk kreatif dan potensi alam serta budaya Indonesia. Kotribusi industri kreatif terhadap PDRB, penyediaan lapangan kerja, peningkatan ekspor terus meningkat seiring dengan berjalannya waktu. Masalah yang dihadapi oleh para pelaku industri kreatif skala mikro kecil dan menengah adalah dinamika dan karakteristik industri kreatif di Indonesia (Bank Indonesia, 2015), keterbatasan SDM, mutu dan standarisasi produk, manajemen proses rendah, (Sumartik dan Larassaty, 2016).

Nugroho dan Cahyadin (-), menyebutkan diperlukan dokumen profil industri kreatif di setiap daerah untuk memudahkan pemerintah dalam merencanakan strategi pengembangan dan peningkatan daya saing di pasar regional dan global. Beberapa daerah sudah menentukan potensi dan prioritas industri kreatif skala kecil dan menengan seperti Sumatra Barat (Pusparini, 2011), Kota Batu Malang ( Fitriana dkk, 2014), Madura (Akhmad dan Hidayat, 2015).

Terkait hal tersebut, Pemerintah Provinsi Banten perlu memetakan potensi dan prioritas industri kreatif skala mikro, kecil dan menengah untuk memudahkan perencanaan strategis untuk pengembangan produk kreatif. Penelitian ini akan memetalkan dan memilih sub sektor industri kreatif potensial dan prioritas skala mikro, kecil dan menengah di Provinsi Banten untuk mempermudah dalam menentukan strategi dan kebijakan pengembangan ke depan lingkup Provinsi Banten.

\section{METODE PENELITIAN}

Penelitian dilakukan selama 5 bulan dimulai dari bulan Juli sampai dengan November 2017 di Provinsi Banten. Pendekatan yang digunakan dalam penelitian ini adalah diskriptif kualitatif yang memaparkan dan menganalisisis terhadap permasalahan mikro, kecil dan menengah industri kreatif. Teknik yang dilakukan oleh peneliti adalah survei literature di bidang terkait ekonomi kreatif dan industri kreatif untuk memperoleh konsep-konsep yang relevan. Pengumpulan data dilakukan melalui penelusuran berbagai sumber baik data primer dan data sekunder. Data primer diperoleh denggan metode kuisioner, wawancara dan FGD, sedangkan data sekunder diperoleh dari sumber data yang relevan seperti dari BPS, Disperindag Provinsi Banten, Disperindag Kabipaten Kota. Analisa data menggunakan Analytical Hyrachy Process (AHP) 
sebagai pendekatan pengambilan keputusan yang dirancang untuk memberikan solusi dari permasalahan yang menyangkut kriteria yang bersifat komplek, dalam menentukan prioritas pilihan-pilihan dengan beberapa kriteria untuk menentukan model alternatif untuk menyelesaikan bermacam-macam masalah.

\section{HASIL DAN PEMBAHASAN}

\section{Peringkat Kriteria Penetapan dan Prioritas Sektor Ekonomi Unggulan.}

Hasil olah data terhadap 11 kriteria yang diuji diperoleh peilaian dari sumber data dan diurutkan berdasarkan nilai jumlah pilihan, yang termasuk kedalam kriteria tertinggi adalah ketersediaan sumber daya manusia termpil pengolah ekraf.dan terendah adalah sarana usaha seperti terlihat pada table 1, dibawah dijelaskan beberapa bobot AHP dan kriteria yang diambil dan diolah dari data hasil survey, seperti Tabel 1.

Tabel 1. Bobot Kriteria Dan Peringkat (Urutan Prioritas) Kriteria Penetapan Subsektor Ekonomi Kreatif Unggulan Di Provinsi Banten

\begin{tabular}{clcc}
\hline No & \multicolumn{1}{c}{ Kriteria } & Jumlah Pilihan & Peringkat \\
\hline 1 & SDM terampil pengolah roduk kreatif & 20 & 1 \\
2 & Promosi tinggi & 15 & 2 \\
3 & Modal & 13 & 3 \\
4 & Teknologi & 11 & 4 \\
5 & Ketersediaan pasar & 9 & 5 \\
6 & Eksistensi peminat & 8 & 6 \\
7 & Produk terbina & 7 & 7 \\
8 & Bahan baku & 6 & 8 \\
9 & Kebijakan pemerintah & 5 & 9 \\
10 & Kualitas pertunjukan / tampilan & 5 & 9 \\
11 & Sarana usaha & 2 & 10 \\
\hline
\end{tabular}

Sumber: Data diolah

Berdasarkan orientasi yang berfokus pada kelompok industri kreatif skala mikro, kecil dan menengah dengan wawancara, selanjutnya dilakukan pengolahan data dengan menggunakan metod AHP diperoleh gambaran bahwa Provinsi Banten memiliki potensi dan peluang besar dalam pengembangan ekonomi kreatif. Dari 16 sektor ekonomi kreatif yang diidentfikasi, didata dan dianalisis diperoleh gambaran bahwa sektor industri kreatif kerajinan yang memiliki peringkat bobot tertinggi dibanding sektor lainnya di Banten, diikuti dengan Fesyen, Kuliner, dan 
subsektor lain yang bobotnya tidak terlalu

tinggi, seperti terlihat pada Tabel 2 .

Tabel 2. Penentuan sub sektor industri kreatif skala mikro, kecil dan menengah

\begin{tabular}{clcc}
\hline No & Subsektor Industri Kreatif & Jumlah Responden & Peringkat \\
\hline 1 & Kuliner & 53 & 1 \\
2 & Kriya & 20 & 2 \\
3 & Fesyen & 13 & 3 \\
4 & Seni Pertunjukan & 8 & 4 \\
5 & Televisi dan radio & 8 & 4 \\
6 & Desain Komputer dan Visual & 5 & 5 \\
7 & Desain Produk & 5 & 5 \\
8 & Film Animasi & 5 & 5 \\
9 & Fotografi & 4 & 6 \\
10 & Disain Interior & 3 & 7 \\
11 & Applikasi dan Game & 1 & 8 \\
12 & Musik & 1 & 8 \\
13 & Penerbitan & 1 & 8 \\
14 & Periklanan & 1 & 8 \\
15 & Arsitektur & 0 & 9 \\
16 & Seni Rupa & 0 & 9 \\
\hline
\end{tabular}

Sumber: Data diolah

Dari jumlah pilihan yang didapat dari hasil survey lapangan, kemudian data dikombinasikan dengan kriteria yang menggambarkan suatu subsektor disebut Sektor Unggulan dengan pilihan 16 subsektor ekonomi kretaif diperoleh bobot menggunakan AHP. Ketiga kriteria tersebut adalah modal, promosi tinggi dan tersedianya SDM pengolah produk kreatif seperti pada Tabel 3 .

Tabel 3. Berdasarkan perhitungan prioritas dengan AHP.

\begin{tabular}{lc}
\hline \multicolumn{1}{c}{ Kriteria } & Prioritas terkecil - terbesar \\
\hline Modal & 0,142857 \\
Promosi Tinggi & 0,285714 \\
Tersedia SDM Pengolah Produk & 0,571429
\end{tabular}

Sumber: Data diolah

Dari 11 kriteria yang diajukan, diperoleh 3 kriteria dengan nilai tertinggi yaitu, tersedianya SDM Pengolah dengan nilai 0,571 , kriteria promosi yang tinggi dengan nilai $0,0.286$, dan modal usaha indutri kreatif dengan nilai 0,43. 
Tabel 4. Subsektor dominan industri Kreatif skala mikro kecil dan menengah

\begin{tabular}{lcc}
\hline Subsektor & Bobot & Peringkat \\
\hline Kuliner & 0,099153439 & 3 \\
Kriya & 0,496243386 & 1 \\
Fesyen & 0,404603175 & 2 \\
\hline
\end{tabular}

Sumber: Data diolah

Dari Table 4 diatas, terlihat tersedianya SDM pengolah Produk merupakan Prioritas pertama di subsektor ekonomi kreatif dengan bobot prioritas 0,571429 diikuti dengan point Promosi Produk Tinggi dengan point 0,285714 dan Modal Usaha sebesar 0,14285. Selanjutnya setelah Kriteria Prioroitas diperoleh, kemudian dilakukan penyilangan data dengan Prioritas Subsektor Ekraf, sehingga diperoleh

\section{Daftar Panjang (Long list) Industri Kriya}

Berdasarkan hasil analisi bobot gabungan dan peringkat tingkat kepentingan diperolah bahwa gambaran sektor ekonomi kreatif terletak pada industri kerajinan, dan hal ini sesuai dengan hasil penelitian Nugroho dan Cahyadin ( - ) yang menunjukkan sektor industri kreatif Kerajinan masih dominan terhadap penyumbang PDRB Nasional angka 0, 496243386 pada posisi pertama untuk Kriya, 0,404603175 untuk subsektor Fesyen pada posisi kedua dan 0,099153439 untuk Subsektor Kuliner pada posisi ketiga. Ketiga Subsektor Ekonomi kreatif ini menjadi Subsektor yang paling dominan dipilih oleh responden dan posisi peringkat diatas menjadi gambaran bagi pemerintah untuk memberikan stimulus lebih pada subsektor yang ada dan menjadi kekuatan utama di Banten.

dari sektor Industri Kreatif. Jenis - Jenis kerjainan yang ada di Provinsi Banten yang merupakan rician dari kerajinan itu sendiri adalah industri kerajinan logam mulia dan bahan dari logam, industri anyaman (perlatan dari rotan atau bambu, pandan, tas dan hiasan dinding lainnya), industri barang dari kulit (sepatu, dompet, sandal), Tekstil (tas, pakaian konveksi), Furniture (kayu, bambu, logam, plastik) dari data ini dikembangkan suatu 
daftar panjang (long list) komoditas

sebagaimana terlihat pada Tabel 5.

Tabel 5. Komoditas unggulan sub sektor kriya industri kreatif di Provinsi Banten 2017

\begin{tabular}{|c|c|c|c|c|}
\hline No & Komoditas & $\begin{array}{l}\text { Jenis Indsutri Yang } \\
\text { Telah Ada }\end{array}$ & Produk & Jumlah Unit IKM \\
\hline 1 & Logam & $\begin{array}{l}\text { Industri kerjainan logam } \\
\text { mulia dan bahan dari logam } \\
\text { (perabot dan perhiasan dari } \\
\text { logam) }\end{array}$ & $\begin{array}{l}\text { Perabot rumah } \\
\text { tangga perhiasan } \\
\text { logam sepuhan } \\
\text { maupun olahan logam } \\
\text { mulia Nugget }\end{array}$ & 360 \\
\hline 2 & Bambu dan Rotan & $\begin{array}{l}\text { Industri kerajinan anyaman } \\
\text { (peralatan dari rotan, bambu, } \\
\text { endong, pandan, tikar tas, dan } \\
\text { hiasan dinding) }\end{array}$ & $\begin{array}{l}\text { Keranjang, Kap } \\
\text { Lampu, Peralatan dari } \\
\text { Rotan / bambu dan } \\
\text { anyaman } \\
\text { tas, hiasan dinding. }\end{array}$ & 57 \\
\hline
\end{tabular}

\begin{tabular}{|c|c|c|c|c|}
\hline 3 & Kulit & $\begin{array}{l}\text { Industri Barang Kulit dan } \\
\text { Alas kaki }\end{array}$ & $\begin{array}{l}\text { Tas, Dompet, Sepatu } \\
\text { Olaharag dan Sepatu } \\
\text { Formal }\end{array}$ & 97 \\
\hline 4 & $\begin{array}{l}\text { Tekstil dan } \\
\text { Produk } \\
\text { Tekstil }\end{array}$ & $\begin{array}{l}\text { Industri Konveksi dan } \\
\text { Indsutri Keset , Lap Majun , } \\
\text { Pesanan }\end{array}$ & $\begin{array}{l}\text { Pakaian jadi, } \\
\text { sTudung, Keset, Lap } \\
\text { Majun dan Tas } \\
\text { Pesanan Petir }\end{array}$ & 348 \\
\hline & Furniture / Mebel & Industri Furniture / Mebel & $\begin{array}{l}\text { Furniture Kayu, } \\
\text { Bambu, Logam dan } \\
\text { Plastik }\end{array}$ & 99 \\
\hline
\end{tabular}

Sumber: Data diolah dan Banten dalam angka, 2017

\section{Daftar Pendek}

Dari hasil evaluasi daftar panjang yang terdapat pada komoditas unggulan maka dikembangkan suatu daftar pendek komoditas unggulan. Secara singkat, komoditas unggulan yang menjadi basis penetapan kompetensi inti industri kreatif di Provinsi Banten ditunjukan dengan Tabel 6.

Tabel 6. Daftar Pendek (Short List) Komoditas Unggulan Indsutri Kreatif Kriya di Provinsi Banten

\begin{tabular}{|c|c|c|c|c|}
\hline No & Komoditas & Jenis Industri & Produk & Jumlah IKM \\
\hline
\end{tabular}




\begin{tabular}{|c|c|c|c|c|}
\hline 1 & Logam & $\begin{array}{l}\text { Industri kerjainan logam mulia } \\
\text { dan bahan dari logam (perabot } \\
\text { dan perhiasan dari logam) }\end{array}$ & $\begin{array}{lrr}\text { Perabot rumah } & \text { tangga } \\
\text { perhiasan logam } & \text { sepuhan } \\
\text { maupun } & \text { olahan } \\
\text { logammuugget } & \end{array}$ & 360 \\
\hline 2 & $\begin{array}{l}\text { Tekstil dan Produk } \\
\text { Tekstil }\end{array}$ & $\begin{array}{l}\text { Industri Konveksi, Industri } \\
\text { Keset, Lap Majun, Tas } \\
\text { Pesanan, baju muslim }\end{array}$ & $\begin{array}{l}\text { Pakaian jadi, Tudung, } \\
\text { Keset, Lap Majun dan Tas } \\
\text { Pesanan Petir }\end{array}$ & 348 \\
\hline
\end{tabular}

Sumber: Banten Dalam Angka 2017

Dari analisa AHP diperoleh 3 Sub sektor dominan industri kreatif skala mikro kecil dan menengah di Provinsi Banten yaitu Kriya, Fesyen dan Kuliner. Dari ketiga subsector tersebut kemudian kita padu silangkan dengan data BPS Provinsi Banten pada industri kreatif mikro kecil dan menengah diaambil nilai tertinggi yaitu Kriya kemudian dibuat long list daftarnya diperoleh 5 jenis industri penyusunnya yaitu logam, kerajinan bambu, kulit, tekstil dan produk tekstil serta furniture. Kemudian dari long list disusun short list sehingga diperoleh industri Logam dengan pelku usaha sebanyak 360 pelaku usaha dan tekstil sebanyak 348 pelaku usaha mikro kecil dan menengah di Provinsi Banten.

\section{KESIMPULAN}

Hasil perhitungan 16 subsektor dibandingkan dengan 11 kriteria dan dianalisis dengan pendekatan AHP diperoleh tiga jenis industri kreatif skala mikro kecil dan menengah di Provinsi Banten yaitu Kriya dengan nilai 0,499,
Fesyen dengan nilai 0,404 dan Kuliner dengan nilai 0,099. Ditentukan Kriya sebagai sub sektor paling dominan, dan kemudian di buat data long list dengan data BPS diperoleh jenis industri dari subsektor kriya yaitu industri kerajinan logam, kerajinan bamboo, kerajinan kulit, kerajinan tekstil dan bahan tekstil serta kerajinan furniture. Dari 5 jenis kerajinan dipilih dua untuk ditentukan sebagai shortlist pengembangan industri kreatif skala mikro, kecil dan menengah yaitu kerajinan Logam dengan jumlah sebanyak 360 pelaku dan kerajinan tekstil dan bahan tekstil sebanyak 348 pelaku.

\section{REKOMENDASI}

Pemerintah Daerah Provinsi Banten perlu melakukan pengembangan intensif (hulu hingga hilir) terhadap tiga Sektor dominan Ekonomi Kreatif yaitu (kriya, fesyen dan kuliner) yang ada di Provinsi Banten melalui Badan Perencanaan Pembangunan Daerah, Dinas Pariwisata dan Dinas Pedagangan dan Perindustrian dengan melibatkan stakeholder tekait 
untuk mendorong peningkatan perekonomian daerah skala IKM.

\section{UCAPAN TERIMAKASIH}

Penulis mengucapkan terimakasih kepada Bapak Drs. Hudaya Latuconsina, M.Si selaku kepala Bappeda Provinsi Banten yang telah memfasilitasi kegiatan penelitian ini sehingga penulis dapat menyelesaikan karya tulis ilmiah ini.

\section{DAFTAR PUSTAKA}

Akhmad, Sabarudin dan R . Hidayat. (2015). Pemetaan Potensi Industri Kreatif Unggulan Madura. Jurnal Sains, teknologi dan Industri Vol. 12 No 2. Hal 155-165.

Antariksa, Basuki. --- . Konsep Ekonomi Kreatif : Peluang dan Tantangannya dalam Pembangunan di Indonesia. Kemenparekraf.

Badan Pusat Statistik, (2017). Banten dalam Angka.BPS

Bank Indonesia, (2015). Kajian Peningkatan Akses Pembuayaan Industri Kreatif di Indonesia. Departemen Pengembangan UMKM. Bank Indonesia

Fahmi, Fikri Zul. (2014). Creative Economy Policy in Developing Country : Case Study in Indonesia. ERSA ${ }^{54 \text { th }}$ Conggress. Saint Pitersburg.

Fitriana, AN., Irwan Noor.,Ainul Hayat. (2014). Pembangunan Industri Kreatif Sektor Kerajinan di Kota
Batu. Studi kasus industtri kreatif sektor kerajinan kota Batu Malang. Jurnal Analisis Kebijakan Publik (JAP) Vo 2, No 2. Hal 281-286.

Hamdan. (2016). Kebijakan dan Strategi Pengembangan Ekonomi Kreatif. Kementerian Bidang Perekonomian Republik Indonesia.

Hilman, M.N. (2016). Big Data Pendukung Ekonomi Kreatif. Badan Ekonomi Kreatif

Howkins. J. (2005). The Creative Economy : Economic Growth. India Jadhpur

Inpres No 6 Tahun 2009 tentang Pengembangan Industri Kreatif.

Kamil, Akhmad. (2015). Industri Kreatif Indonesia : Pendekatan Analisis Kinerja Industri. Jurnal Media Trend, Vol. 10 No 2. Hal 207225.

Maryunani, SR., IS,Miryanti. (2014). The development of Entrerpreneur in Creative Industries with Reference to Bandung as Creative City. The $6^{\text {th }}$ Indonesia International Conference on Innovation, Entrepreneurship and Small Business.

Nugroho, P Setyo dan Cahyadin, M. ( - ), Analisis Perkembangan Industri Kreatif di Indonesia. Universitas Sebelas Maret.

Perpres No 15 Tahun 2015 tentang Badan Ekonomi Kreatif (Bekraf)

Pusparini, Hesti. (2011). Strategi Pembangunan Industri Kreatifdi Sumatera Barat. Studi kasus 
Industri Kreatif, sub sektor Kerajinan Bordit/Sulaman dan Tenun. Universitas Andalas. Padang.

Sasongko, Adipradana Idbal. (2014). Strategic Intention and Financial Suuport on MSMEes : An Investigation Study In Indonesia Creative Industri. Integrated Business and Economic Research Review.

Sumatik dan A.L. Larassaty. (2016). Geliat Ekonomi Kreatif Untuk Meningkatkan Branding UMKM di Sidoarjo. Proseding Seminar Nasional Indocompaq. Jakarta.

Suryana., AK, Yuliawati., $\mathrm{R}$ Rofaida (2009). Pengembangan Model Ekonomi Kreatif melalui Value Chain Strategy untuk Kelompok Usaha Kecil (Studi Pada Industri Kerajinan Jawa Barat). UPI.Bandung 